LA-UR- $\theta=158$

Title: $\begin{aligned} & \text { ATTACK OPTIMIZATION AT } \\ & \text { MODERATE FORCE LEVELS }\end{aligned}$

Author(s): $\begin{aligned} \text { Gregory H. Canavan, DDP } & \text { Jul } 251997 \\ \text { U } & \end{aligned}$

Submitted to:

For discussions outside the Laboratory

DISTRIBUTION OF THIS DOCUMENT IS UNLIMITED

Date: April 1997

DISCLAIMER

This report was prepared as an account of work sponsored by an agency of the United States Government. Neither the United States Government nor any agency thereof, nor any of their employees, makes any warranty, express or implied, or assumes any legal liability or responsibility for the accuracy, completeness, or usefulness of any information, apparatus, product, or process disclosed, or represents that its use would not infringe privately owned rights. Reference herein to any specific commercial product, process, or service by trade name, trademark, manufacturer, or otherwise does not necessarily constitute or imply its endorsement, recommendation, or favoring by the United States Government or any agency thereof. The views and opinions of authors expressed herein do not necessarily state or reflect those of the United States Government or any agency thereof.
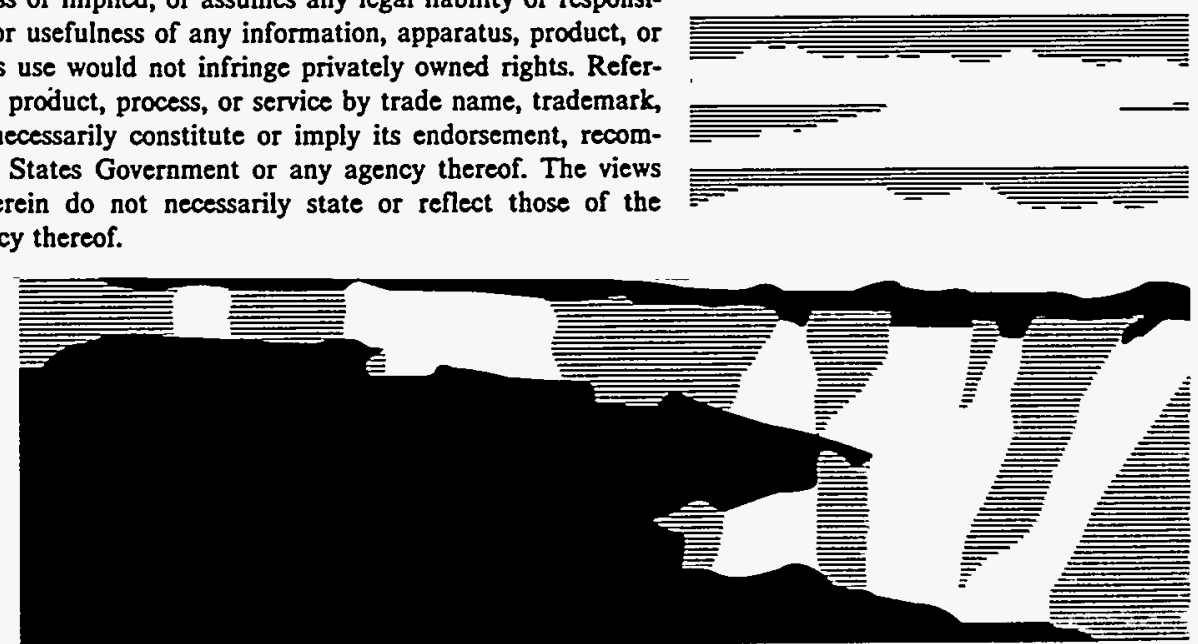

NATIONAL LABORATORY

Los Alamos National Laboratory, an affirmative action/equal opportunity employer, is operated by the University of California for the U.S. Department of Energy under contract W-7405-ENG-36. By acceptance of this article, the publisher recognizes that the U.S. Government retains a nonexclusive, royalty-free license to publish or reproduce the published form of this contribution, or to allow others to do so, for U.S. Government purposes. The Los Alamos National Laboratory requests that the publisher identify this article as work performed under the auspices of the U.S. Department of Energy. 


\section{DISCLAIMER}

Portions of this document may be illegible in electronic image products. Images are produced from the best available original document. 


\title{
ATTACK OPTIMIZATION AT MODERATE FORCE LEVELS
}

\author{
Gregory H. Canavan
}

Optimal offensive missile allocations for moderate offensive and defensive forces are derived and used to study their sensitivity to force structure parameters. levels. It is shown that the first strike cost is a product of the number of missiles and a function of the optimum allocation. Thus, the conditions under which the number of missiles should increase or decrease in time is also determined by this allocation.

This note derives optimal offensive missile allocations between missiles and value forces for moderate offensive and defensive forces. Exchanges are modeled probabalistically, and their results are converted into first and second strike costs through approximations to the value target sets held at risk. The stability index is taken to be their ratio, although minimization of first strike costs is the principal concern. For vulnerable missiles it is possible to analytically derive the value of the allocation that minimizes the first strike cost for any given attack preference, number of weapons per missile, and kill probability. For moderate forces, these allocations, which agree well with numerical optimizations vary strongly with attack preference for few weapons per missile. They fall more slowly for larger numbers. Adding survivable missiles in equal numbers decreases the allocation to missiles by about a factor of two, in agreement with numerical optimizations. Adding defenses increases allocations to missiles.

For moderate forces, the derivative of the first strike cost with respect to the number of missiles is a function of the optimal allocation. Thus, these optima can be used to examine the variation of costs. For vulnerable missiles, the derivative is positive for small numbers of weapons per missile and attack preferences, which means the attacker should reduce the number of missiles and weapons to reduce first strike costs. The derivative is negative for large numbers of weapons per missile and attack preferences, which means he should increase the number of missiles and weapons. Unfortunately, the transition occurs at roughly the current number of weapons per missile and at roughly the attack preferences used in current analyses.

Survivable missiles shift make the derivative positive for all values of weapons per missile for small attack preferences, although still negative for large values. The transition occurs at the attack preference where the first striker gives roughly equal priority to inflicting damage on the other and preventing damage to himself. To apply these results it is necessary to have a good estimate of the opponent's preference, on which the transition depends strongly. Of course, the other's preference cannot be known with certainty. Defenses make the derivative smaller as defenses increase. There is a transitional region in which the derivative-and hence incentive for 
missile growth-is small for all values of defenses. However, it occurs at a smaller value of attack preference than that in the absence of defenses.

Review of earlier results. It is possible to model exchanges between symmetric missiles forces in terms of the first, F, and second, S, strikes that they could deliver. For a force of $M$ vulnerable missiles with $\mathrm{m}$ weapons each and $\mathrm{N}$ invulnerable missiles with $\mathrm{n}$ weapons each, of which a fraction $\mathrm{f}$ is directed at the opponent's missiles, the first strike on value targets is

$$
\mathrm{F}=(1-\mathrm{f})(\mathrm{mM}+\mathrm{nN}) \text {. }
$$

The average number of weapons delivered on each opponent vulnerable missile is

$$
\mathrm{r}=\mathrm{f}(\mathrm{mM}+\mathrm{nN}) / \mathrm{M} \text {. }
$$

For $r$ large, the average probability of survival is approximately 1

$$
\mathrm{Q} \approx \mathrm{q}^{\mathrm{r}} \text {, }
$$

where $q=1-p$, and $p$ is the attacking missile's single shot probability of kill, which is taken to be the same for all missiles. The second strike is

$$
\mathrm{S}=\mathrm{mMQ}+\mathrm{nN} \approx \mathrm{mMq}^{\mathrm{r}}+\mathrm{nN} \text {. }
$$

$S$ is delivered on value targets as missiles remaining at the end of the exchange have no value.

Costs and stability index. These first and second strike magnitudes can be converted into the costs of striking first and second through exponential approximations to the fraction of the value targets destroyed. The cost of damage to self and of incomplete damage to the other fall on different parties; thus, they are incommensurate. A conventional approximation is to take their weighted sum ${ }^{2}$

$$
\mathrm{C}_{1}=\left(1-\mathrm{e}^{-\mathrm{kS}}+\mathrm{Le}-\mathrm{kF}\right) /(1+\mathrm{L})
$$

where $k \approx 0.001$ is a constant roughly equal to the inverse of the size of the value target sets held at risk 3 and $L$ is a constant that represents the attacker's relative preference for inflicting damage on the other and preventing damage to self. L small means the first striker is primarily concerned about denying damage; $\mathrm{L}$ large means he is more concerned about inflicting damage on the other. It is generally assumed $\mathrm{L} \leq 1$, although there is no fundamental reason. The construction of $\mathrm{C}_{1}$ as a weighted averages of the cost to self and other is plausible but not unique. ${ }^{4}$ The normalized second strike costs cost to for the second striker, who must ride out the first strike $F$, is

$$
C_{2}=\left(1-e^{-k F}+L e^{-k S}\right) /(1+L) \text {, }
$$

which uses the same constant $\mathrm{L}$ used above, an assumption that is explored elsewhere. 5 There is additional arbitrariness in converting $C_{1}$ and $C_{2}$ into stability indices. ${ }^{6}$ The ratio of costs $C_{1} / C_{2}$ is used below based on simple arguments. If the cost of striking first, $\mathrm{C}_{1}$, is large, the first striker should be deterred from initiating an exchange. Similarly, if the cost of striking second, $\mathrm{C}_{2}$, is small, both sides should see little penalty in riding out a crisis. The ratio $\mathrm{C}_{1} / \mathrm{C}_{2}$ captures both of these effects in a single stability index

$$
\mathrm{I}=\mathrm{C}_{1} / \mathrm{C}_{2}=\left(1-\mathrm{e}^{-\mathrm{kS}}+\mathrm{Le}-\mathrm{kF}\right) /\left(1-\mathrm{e}^{-\mathrm{kF}}+\mathrm{L} \mathrm{e}^{-\mathrm{kS}}\right)
$$


Vulnerable missiles. The optimizations for vulnerable missiles, mixes, and defenses are presented sequentially to simplify the discussion. For vulnerable missiles, Eqs. (1) - (4) reduce to

$$
\begin{aligned}
& F=(1-f) m M, \\
& r=f(m M) / M=f m, \\
& Q \approx q^{r}=q^{f m}, \\
& S=m M Q \approx m M q^{r} .
\end{aligned}
$$

The attacker wishes to minimize the first strike cost $C_{1}$, which for moderate forces $F, S \ll 1 / \mathrm{mk}$ reduces to

$$
\mathrm{C}_{1}=[\mathrm{L}+\mathrm{k}(\mathrm{S}-\mathrm{LF})] /(1+\mathrm{L})=\left\{\mathrm{L}+\mathrm{k}\left[\mathrm{mMq}^{\mathrm{fm}}-\mathrm{L}(1-\mathrm{f}) \mathrm{mM}\right\} /(1+\mathrm{L}),\right.
$$

whose minimum can be found by differentiation with respect to $f$ and setting the result to zero. That produces the analytic allocation

$$
\mathrm{f}_{\mathrm{a}}=\ln (-\mathrm{L} / \mathrm{m} \ln \mathrm{q}) /(\mathrm{m} \operatorname{lnq}) \text {, }
$$

which depends inversely on $\mathrm{m}$, but depends only logarithmically on $\mathrm{L}$ and q. Figure 1 shows the optimal allocations of vulnerable one and three warhead missiles. The curve for three warheads falls gradually from 1 to $\approx 0.15$ as $L$ increases from $L=0.1$ to $L=1.7$. The curve for the single warhead missile is limited to unity below $L \approx 0.4$ and to zero for $L>0.9$, i.e., all weapons are allocated to missiles at small $\mathrm{L}$ and none are at large $\mathrm{L}$.

Figure 2 compares $f_{a}$ from Eq. (13) with the result of iterative, numerical solution used in earlier reports. The agreement is nearly exact to $m=2$. The discrepancy increases to about $10 \%$ by $\mathrm{m}=5$ and $25 \%$ by $\mathrm{m}=9$. The first corresponds to $\mathrm{mM}=200$ weapons, where the assumption that $\mathrm{mM}<1 / \mathrm{k}=1,000$ is satisfied. The second corresponds to $\mathrm{kmM}=0.5$, so some error is expected. The third corresponds to $\mathrm{kmM}=0.9$, so it is surprising that the analytic optimization is so accurate. Results for other values suggest that the analytic optimization is sufficiently accurate for most forces of interest in large reductions.

The optimal $f_{a}$ of Eq. (13) can be substituted into Eq. (12) to determine the value of $C_{1}$ corresponding to that value of $\mathrm{m}$, which can be rewritten as

$$
C_{1}=\left\{L+k m M\left[q^{f m}-L(1-f)\right]\right\} /(1+L),
$$

in which the term $L /(1+L)$ is a function of $L$ only and the second term is a product of $\mathrm{kmM}$ and a function of $m, L$, and $q$. For a given $L$, the derivative of $C_{1}$ with respect to $M$ is

$$
\partial C_{1} / \partial(k M)=m\left[q^{f m}-L(1-f)\right] /(1+L),
$$

which is shown in Fig. 3. For $m=1$, single weapon missiles, the derivative is about 0.4 for all $\mathrm{L}$ from 0.1 to 0.5 . The derivative falls with $L-$ the more rapidly at greater $L$. For $L=0.5,0.3$, and 0.1 it reaches zero at $m \approx 3,4$, and 5 , respectively. It falls rapidly for large $L$.

For positive values of the derivative, the first striker should minimize first strike costs by reducing the number of his missiles and warheads, as the product $(\mathrm{dM}) \partial \mathrm{C}_{1} / \partial \mathrm{M}$ would then be negative, which would reduce $C_{1}$. For negative values, the first striker should minimize costs by 
increasing the number of his missiles and warheads, as the product $(\mathrm{dM}) \partial \mathrm{C}_{1} / \partial \mathrm{M}$ would be negative, which would again reduce $\mathrm{C}_{1}$. Thus, the combination of parameters for which the derivative is zero defines the boundary between temporal growth or decay of offensive forces seen in companion studies. ${ }^{7}$

Mixes. For survivable missiles, Eqs. (1) - (4) can be used directly. Using $\mathrm{W}=\mathrm{mM}+\mathrm{nN}$ for the total number of weapons and repeating the derivation of Eq. (13) leads to

$$
\mathrm{f}_{\mathrm{a}}=\ln (-\mathrm{L} / \mathrm{m} \ln \mathrm{q}) \mathrm{M} /(\mathrm{W} \operatorname{lnq}) \text {, }
$$

which reduces to Eq. (13) for $N=0$ and $W=m M$. The analytic and numerical optimal allocations are shown in Fig. 4 for $N=M=50$ and $n=m$. The agreement is very good to $m=4-$ 5.; it is about $10 \%$ at $m=9$. The allocation is reduced by about a factor of $M /(M+N)=1 / 2$ from that of Eq. 2 for vulnerable missiles. Repeating the derivation of Eq. (15) produces

$$
\partial \mathrm{C}_{1 / \partial(\mathrm{kM})}=\mathrm{m}\left[\mathrm{q}^{\mathrm{r}}-2 \mathrm{~L}(1-\mathrm{f})\right] /(1+\mathrm{L}),
$$

which is shown as a function of $m$ and $L$ in Fig. 5 for $M=N$. For $m=1$, the derivatives vary from $\approx 1$ to -0.5 for $L=1 / 3$ to $5 / 3$. For $L=1 / 3$, the derivative increases throughout. For $L=2 / 3$, it first increases and then falls slowly. For $L=4 / 3$ and $5 / 3$, the derivatives fall strongly throughout. For $\mathrm{L}=1$, the derivative increases slightly through two weapon missiles and then falls, passing through zero at $m=4$. For initial configurations from $m=1$ to 4 , the optimal strategy would be for the attacker to reduce the number of weapons and missiles. For larger $\mathrm{m}$, the optimal strategy would be to increase them. In this decision, a key parameter is the relative attack preference $L$, as a small variation could shift the decision from decrease to increase. In that decision it is necessary to estimate the opponent's value of $L$, which cannot be known precisely.

Defenses. For $D$ random subtractive defenses, Eqs. (1) becomes

$$
F=(1-f)(m M+n N)[1-D /(M+N)],
$$

where $1-D /(M+N)$ is the fraction of the missiles that penetrate the defenses. ${ }^{8}$ While the optimization can be carried through for arbitrary parameters, the essential results are illustrated for $m=n$, for which $F$ simplifies to

$$
F=(1-f) m(M+N-D),
$$

i.e., the first strike is equal to the number of missiles that penetrate the subtractive defense times the number of weapons carried by each and the fraction allocated to value. The average number of weapons delivered on each vulnerable missile is

$$
\begin{aligned}
& r=f(m M+n N)[1-D /(M+N)] / M=f m(M+N-D) / M, \\
& Q \approx q^{r}=q^{f m}(M+N-D) / M, \\
& S=(m M Q+n N)[1-D /(M Q+N)] \approx m\left(M q^{r}+N-D\right), \\
& C_{1} \approx\left\{L+k\left[m\left(M q^{r}+N-D\right)-L(1-f) m(M+N-D)\right\} /(1+L) .\right.
\end{aligned}
$$

Differentiating as before leads to

$$
f_{\mathrm{a}}=\ln (-\mathrm{L} / \mathrm{m} \ln \mathrm{q})(\mathrm{M} / \mathrm{m}) /(\mathrm{M}+\mathrm{N}-\mathrm{D}) \ln \mathrm{q}
$$


which reduces to the previous results for $D=0$. Figure 6 compares the optimal allocation from $f_{a}$ with the numerical iterations used earlier. The agreement is good over the range shown.

However, for larger $\mathrm{D}$, the second strike can fall to zero, i.e., $\mathrm{Mq}^{\mathrm{r}}+\mathrm{N}<\mathrm{D}$, in which case the first term in Eq. (23) falls to zero, and the second term in $\mathrm{C}_{1}$, is minimized by the choice $f=0$, as in the earlier analytic treatments. ${ }^{9}$

Figure 7 shows the variation of the derivative $\partial C_{1} / \partial(\mathrm{kM})$ with respect to $\mathrm{D}$ and $\mathrm{L}$. The values of the derivative vary from $\approx 2$ to -1 for $L$ small, but converge for large $L$, where they range from about 0.25 to -0.75 . The values for $L=0.25$ and 0.5 are positive throughout, which suggests that the attacker should reduce his weapons for advantage. The values for $\mathrm{L}=1$ and 1.25 are negative throughout, which suggests that the attacker should increase the number of weapons. For $L=0.75$, the value stays close to zero, which indicates that missiles could persist at any given level for some period of time. These trends are altered for large numbers of defenses, as discussed in earlier reports.

Summary and conclusions. This note derives optimal offensive missile allocations between missiles and value forces for moderate offensive and defensive force levels and compares them to previous numerical solutions. The analytic solutions are generally seen to be sufficiently accurate to be used in studies of significant force reductions.

The exchanges are modeled probabalistically, and the results are converted into first and second strike costs through approximations to the value target sets held at risk. The stability index is taken to be their ratio, although the minimization of the first strike cost is the principal concern. For vulnerable missiles it is possible to analytically derive the value of the allocation that minimizes the first strike cost for any given attack preference, number of weapons per missile, and kill probability. For moderate forces, these allocations vary strongly with attack preference for few weapons per missile, but fall more slowly for larger numbers, in agreement with numerical optimizations. The addition of survivable missiles in equal numbers decreases the allocation to missiles by about a factor of two, in agreement with earlier numerical optimizations. Defenses increase the allocation to missiles because they degrade the effectiveness of attacks.

For moderate forces, the derivative of the first strike cost with respect to the number of missiles is a function of the optimal allocation. Thus, the above optima can be used to examine the variation of that derivative with the number of weapons per missile and attack preference. For vulnerable missiles, the derivative is positive for small numbers of weapons per missile and attack preferences, so the attacker should reduce the number of missiles and weapons to reduce the first strike cost. The derivative is negative for large numbers of weapons per missile and attack preferences, so the attacker should increase the number of missiles and weapons. Unfortunately, the transition occurs at roughly the current number of weapons per missile and the attack preferences used in current analyses. 
The addition of survivable missiles shifts the derivative so that it is positive for all values of weapons per missile for small attack preferences, although it is still negative for large values. The transition occurs at roughly the attack preference where the first striker gives equal priority to inflicting damage on the other and preventing damage to self. However, to apply these results it is necessary to have a good estimate of the opponent's preference, on which the transition depends strongly. The addition of defenses causes the derivatives to become smaller for moderate levels of defenses. There is again a transitional region in which the derivative-and hence incentive for missile growth-is small for all values of defenses, but that transition occurs at a somewhat smaller value of the attack preference than that encountered in the absence of defenses.

\section{References}

1. G. Canavan, "Probability of Survival from Multiple Weapon Attacks," Los Alamos report LAUR-97-, February 1997.

2. G. Kent and R. DeValk, "Strategic Defenses and the Transition to Assured Survival," RAND Report R-3369-AF, October, 1986.

3. G. Canavan, "Costs of Strikes Between Vulnerable Missile Forces," Los Alamos report LAUR-97-, February 1997.

4. G. Canavan, "Stability at Symmetric Low Force Levels," op. cit.

5. G. Canavan, "Destabilizing Effects of Perceptions," Los Alamos LA-UR-96-1742, May 1996

6. G. Canavan, "Impact of Differing Metrics on Crisis Stability Analyses," A. Zichichi ed., International Seminar on Nuclear War and Planetary Emergencies, 18th Session: Global Stability Through Disarmament (London, World Scientific, 1993).

7. G. Canavan, "Optimal Time Dependent Deployment of Missile Forces," Los Alamos report LA-UR-97-1379, April 1997.

8. G. Canavan, "Stability of Missile Forces and Defenses," Los Alamos report LA-UR-97-1223, April 1997.

9. G. Canavan, "Destabilizing Effects of Perceptions." op. cit. 


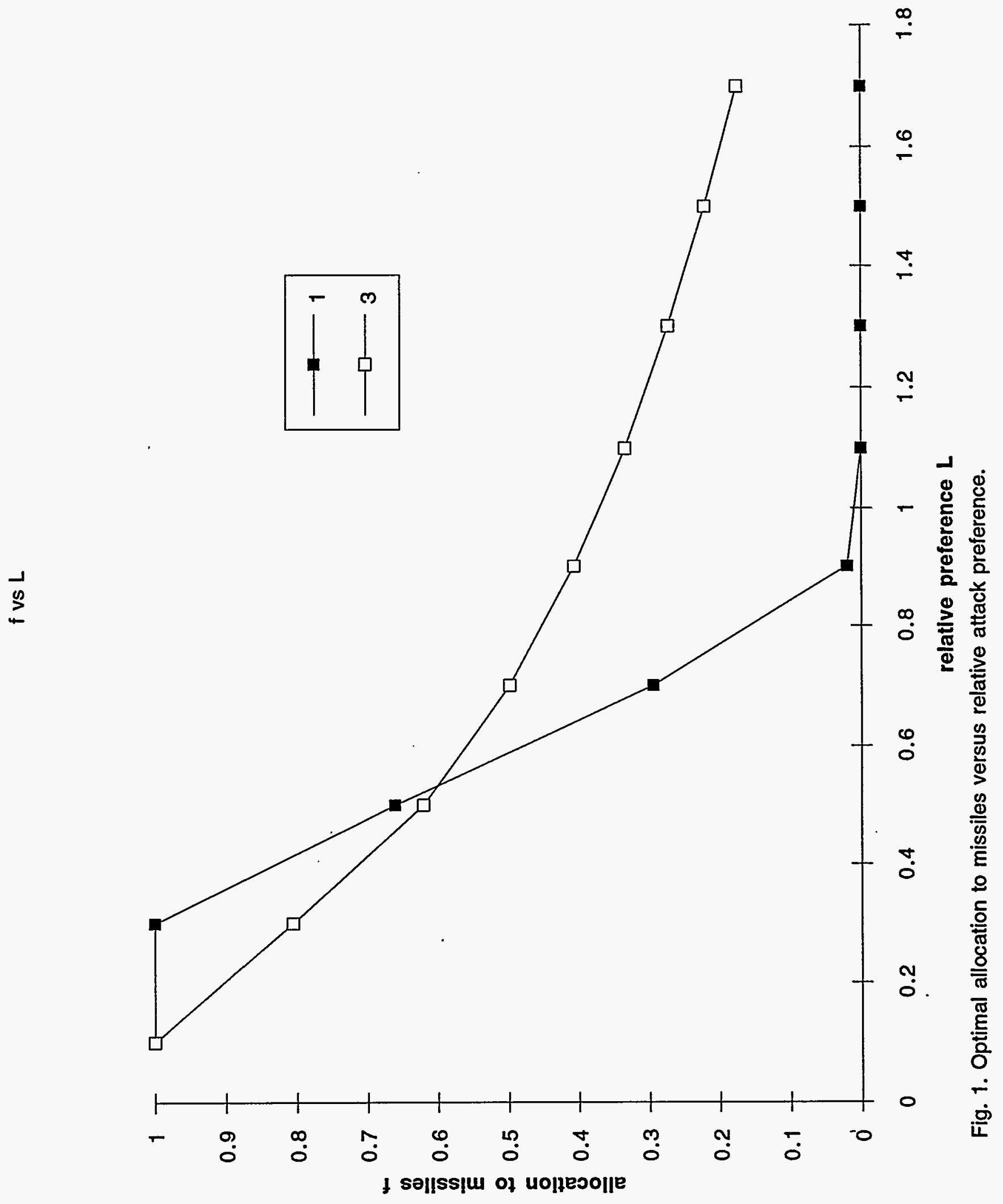




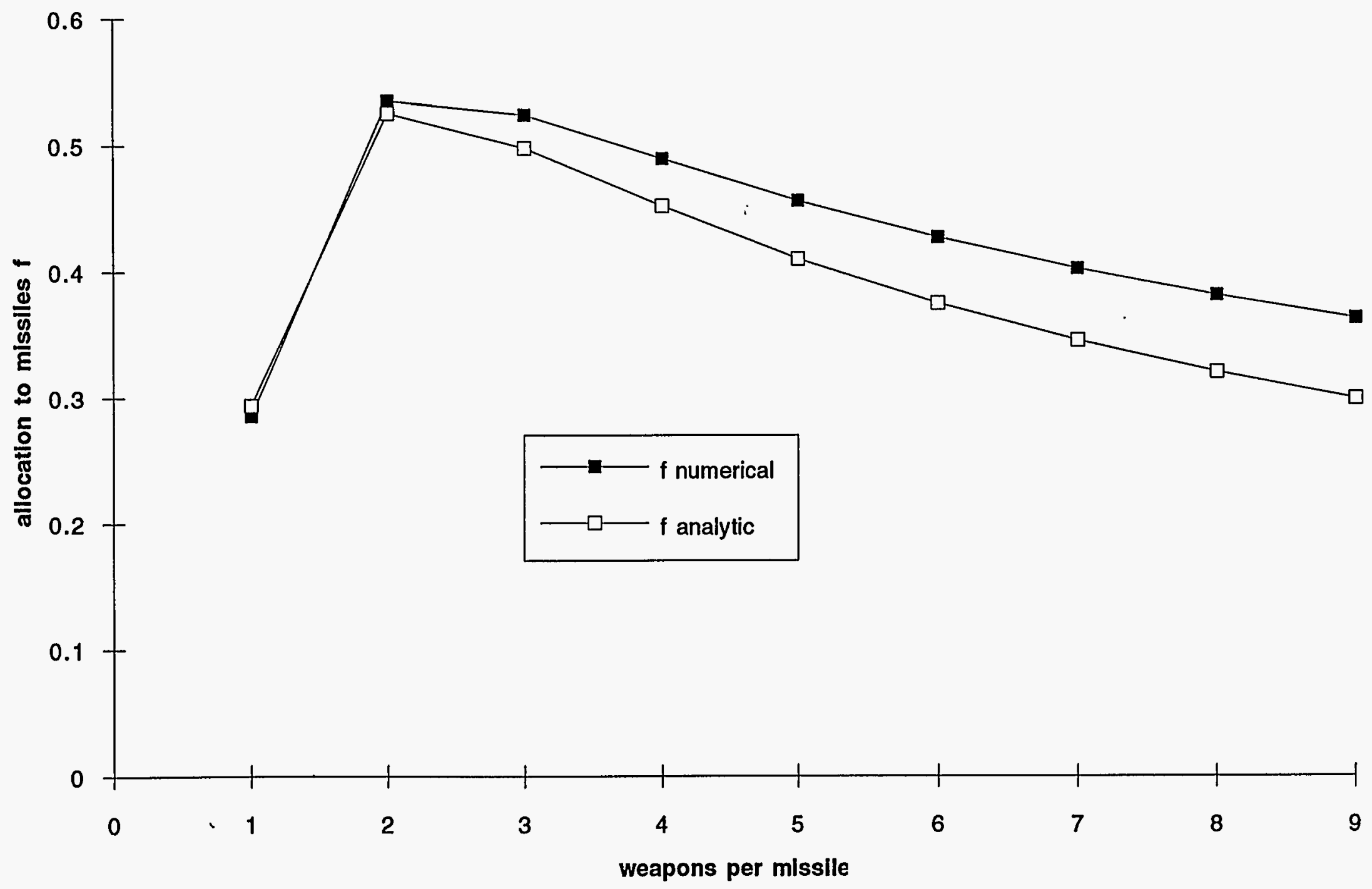

Fig. 2. Analytic and numerical allocations to missiles versus weapons per missile for 100 missiles. 


\section{$d C 1 / d M$ vs $m ; L$}

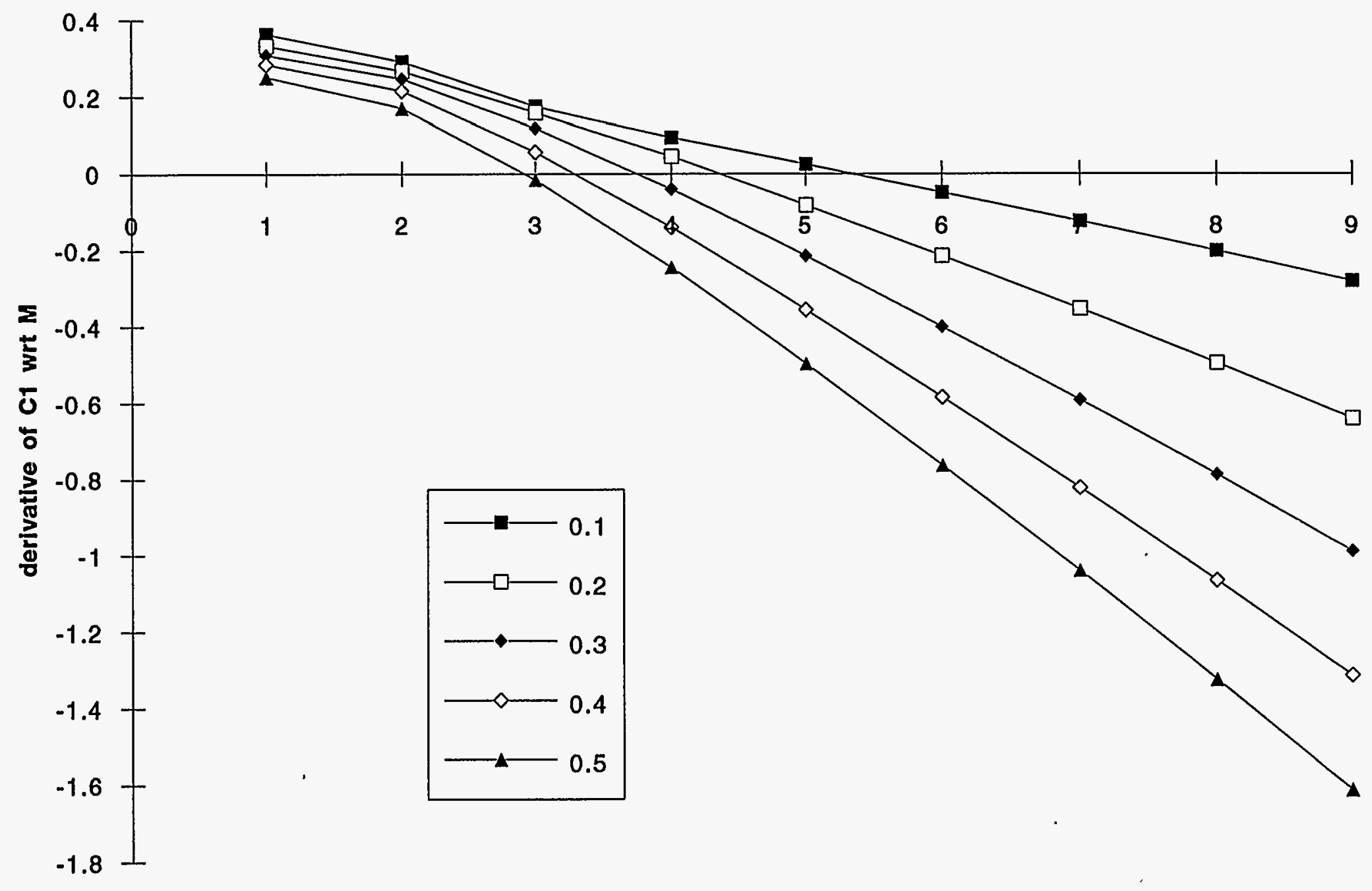

Fig. 3. Derivative of first strike cost with respect to missiles vs weapons per missile for various $L$. 
$f$ vs $m ; M=N=50$

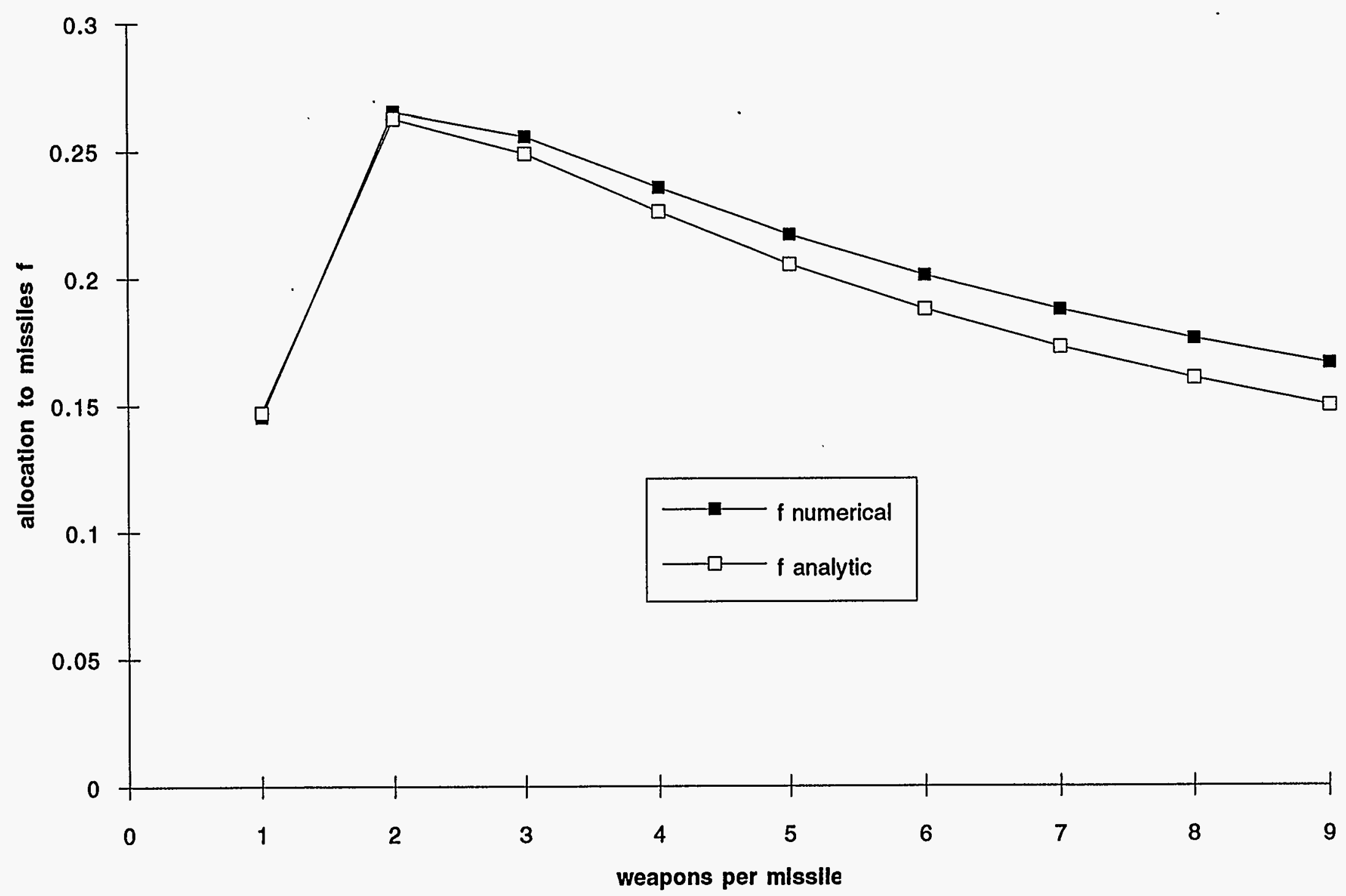

Fig. 4. Analytic and numerical allocations vs weapons per missile for 100 missiles, of which half are survivable. 


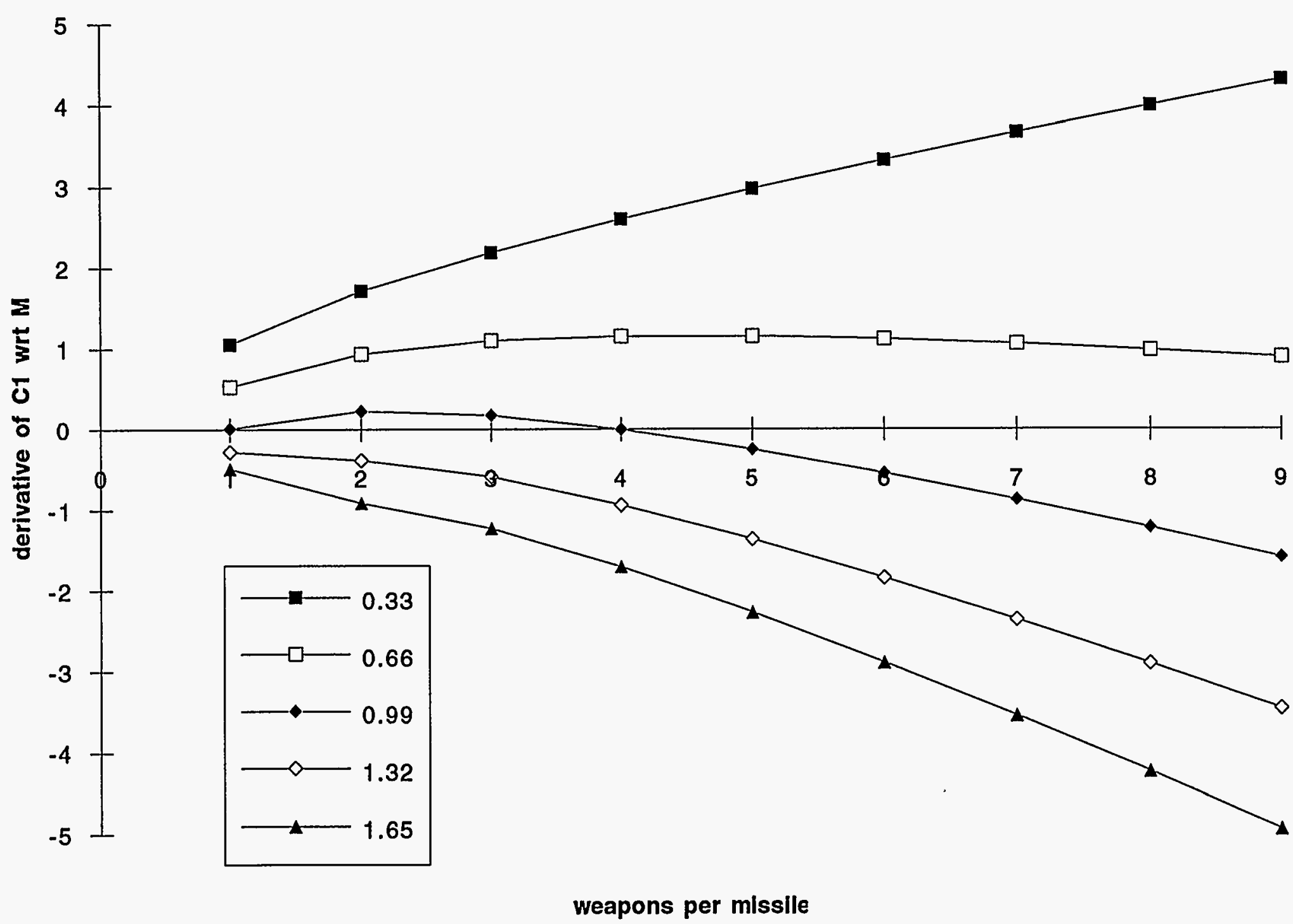

Fig. 5. Derivative of first strike cost with respect to $M=N$ missiles vs $m$ for various $L$. 
f num \& anal vs Def

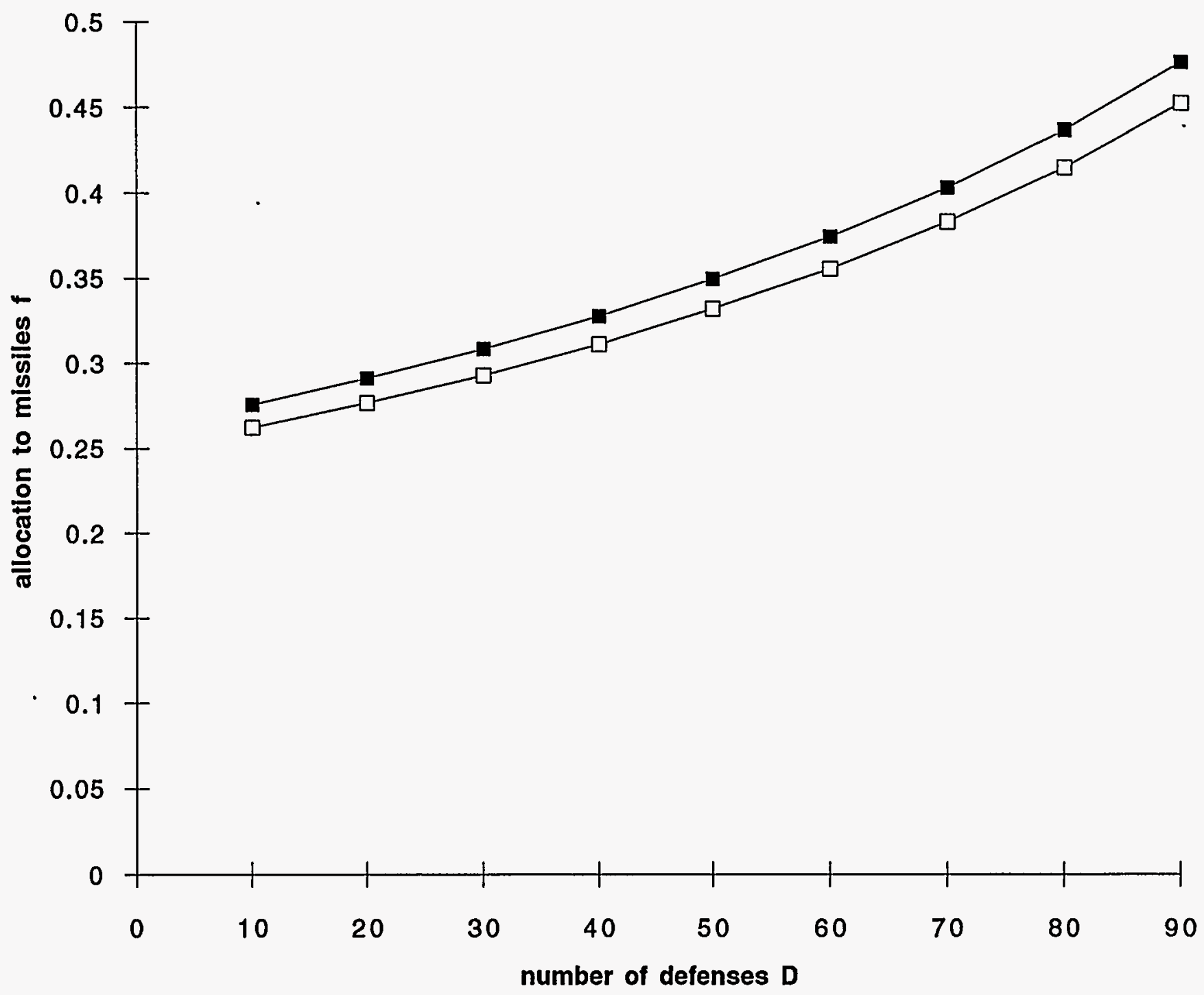

Fig. 6. Numerical and analytic allocations versus defenses for $M=N=100$ and $m=n=3$. 


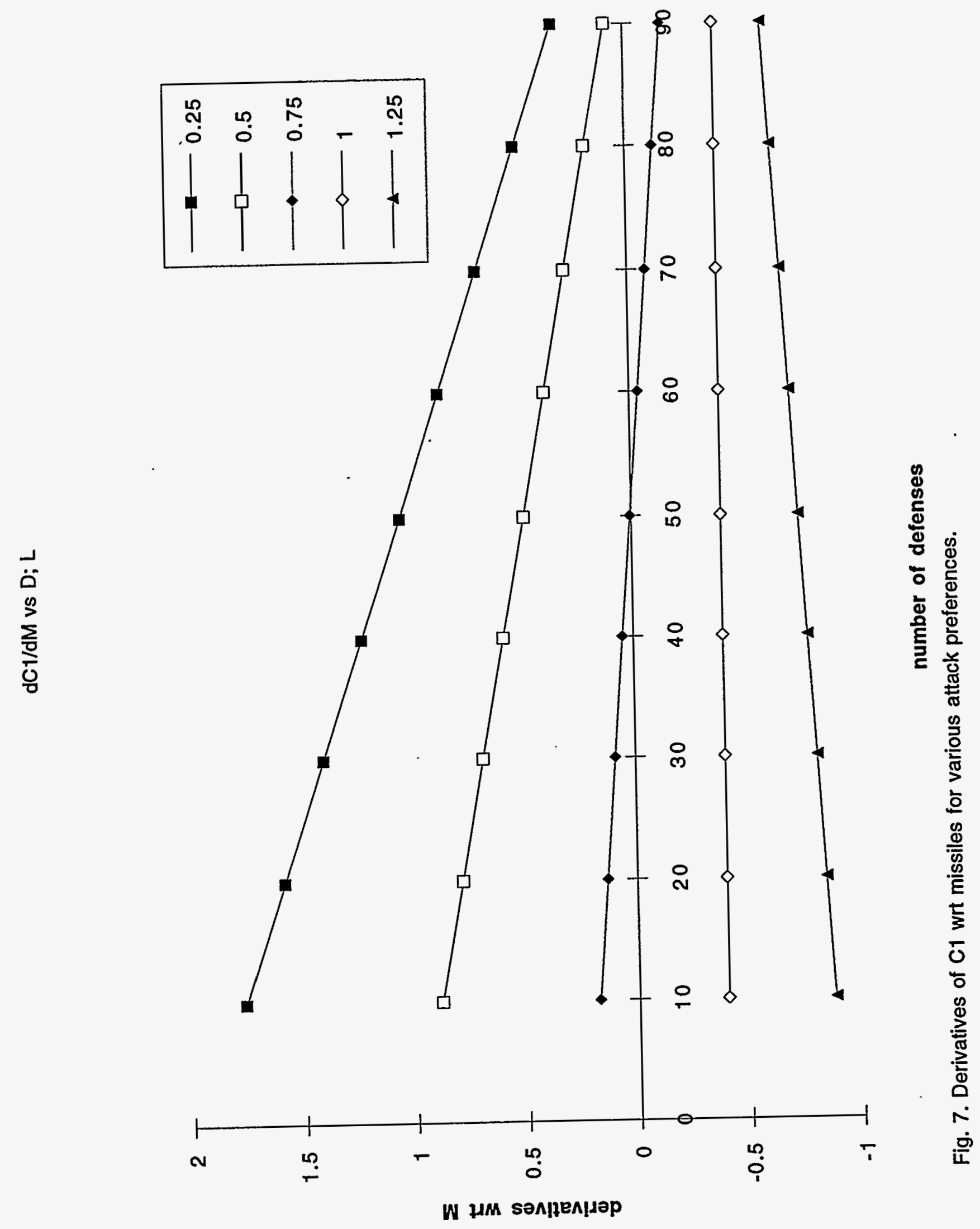

